\title{
State medical malpractice laws and utilization of surgical treatment for rotator cuff tear and proximal humerus fracture: an observational cohort study
}

\author{
Brian Chen ${ }^{1 * \dagger}$, Cole Chapmann ${ }^{2 \dagger}$, Sarah Bauer Floyd ${ }^{3}$, John Mobley ${ }^{4}$ and John Brooks ${ }^{5}$
}

\begin{abstract}
Background: How much does the medical malpractice system affect treatment decisions in orthopaedics? To further this inquiry, we sought to assess whether malpractice liability is associated with differences in surgery rates among elderly orthopaedic patients.

Methods: Medicare data were obtained for patients with a rotator cuff tear or proximal humerus fracture in 2011. Multivariate regressions were used to assess whether the probability of surgery is associated with various state-level rules that increase or decrease malpractice liability risks.

Results: Study results indicate that lower liability is associated with higher surgery rates. States with joint and several liability, caps on punitive damages, and punitive evidence rule had surgery rates that were respectively 5\%-, $1 \%$-, and 1\%-point higher for rotator cuff tears, and 2\%-, 2\%- and 1\%-point higher for proximal humerus fractures. Conversely, greater liability is associated with lower surgery rates, respectively $6 \%$ - and $9 \%$-points lower for rotator cuff patients in states with comparative negligence and pure comparative negligence.

Conclusions: Medical malpractice liability is associated with orthopaedic treatment choices. Future research should investigate whether treatment differences result in health outcome changes to assess the costs and benefits of the medical liability system.
\end{abstract}

Keywords: Medical malpractice, Defensive medicine, Orthopaedics, Medicare

\section{Introduction}

Does the medical malpractice system affect the practice of medicine? We ask this question in the context of orthopaedics, a medical specialty that accounts for $\$ 176$ billion in direct annual healthcare expenditures and affects one in every two Americans over age 18 [1-3]. Orthopaedics is also a field with substantial physician

\footnotetext{
* Correspondence: bchen@mailbox.sc.edu

${ }^{\dagger}$ Brian Chen and Cole Chapman are joint First Authors.

'Department of Health Services Policy and Management, University of South Carolina, 915 Greene Street Suite 354, Columbia, SC 29205, USA

Full list of author information is available at the end of the article
}

discretion because very little level I evidence exists to guide treatment choices [4-19]. Orthopaedics is also a high-risk specialty, and orthopaedic surgeons are among the most commonly sued physicians for medical malpractice, with a high ratio of claims paid out to claims made [20]. As a result, orthopaedic surgeons may be especially sensitive to medical malpractice liability regimes when making their treatment recommendations, with far-reaching implications for healthcare costs and patient outcomes.

Debate over the desirability of medical malpractice laws remains a contentious issue. In addition to the

C C The Author(s). 2021 Open Access This article is licensed under a Creative Commons Attribution 4.0 International License, which permits use, sharing, adaptation, distribution and reproduction in any medium or format, as long as you give appropriate credit to the original author(s) and the source, provide a link to the Creative Commons licence, and indicate if changes were made. The images or other third party material in this article are included in the article's Creative Commons licence, unless indicated otherwise in a credit line to the material. If material is not included in the article's Creative Commons licence and your intended use is not permitted by statutory regulation or exceeds the permitted use, you will need to obtain permission directly from the copyright holder. To view a copy of this licence, visit http://creativecommons.org/licenses/by/4.0/ The Creative Commons Public Domain Dedication waiver (http://creativecommons.org/publicdomain/zero/1.0/) applies to the data made available in this article, unless otherwise stated in a credit line to the data. 
direct costs of litigation, medical malpractice may increase costs indirectly through "defensive medicine," defined as medical practices that reduce legal liability without significant benefit to patients [21, 22]. For example, physicians may order diagnostic tests such as CAT scans, MRIs and X-rays when such actions are not likely to improve patient health ("positive defensive medicine") [23]. The fear of liability may also discourage physicians from performing medically necessary but high-risk procedures ("negative defensive medicine") [24]. Concerns over the adverse cost impact of defensive medicine ultimately provided the political impetus for medical malpractice liability reforms (and more generally, tort reforms) at the state level in the late 1990s. ${ }^{1}$ These reforms primarily limited awards to patients or created procedural barriers for patients to sue their physicians [29].

The objective of this study was to empirically assess whether state tort regimes are associated with surgery rates for two common shoulder conditions to explore defensive medicine in orthopaedics. Our hypothesis is that tort rules that lower legal liability could encourage physicians to undertake greater risk and therefore increase utilization of orthopaedic surgeries. We also hypothesize the converse, that tort rules that increase liability are associated with reductions in orthopaedic surgical procedures.

Our study contributes to the vast literature on medical malpractice in several ways. Existing research has shown little consistent relationship between tort liability and measures of defensive medical practices [30,31], possibly because studies investigate different medical contexts. Most studies focus on obstetrics/gynecology [32-49] or chronic conditions such as heart disease [50-52],

\footnotetext{
${ }^{1}$ Research has shown that the cost of "defensive medicine" is fairly limited. However, in the period leading to the wave of state tort reforms, the common perception was that frivolous medical malpractice lawsuits against physicians increased healthcare expenditures and clogged the courts. Legal reforms to limit medical malpractice claims were therefore thought to provide a solution to the perceived impending crisis. Subsequent studies, however, suggest that the reality is far more nuanced. In a comprehensive review, Sloan and Chepke [25] argued that four discrete segments (legal, medical malpractice insurance, medical care, and government activity) interact to result in a highly complex medical malpractice environment. Avraham et al. [26] found, for example, that some tort reforms reduced insurance premiums, but only for employer-sponsored plans rather than capitated HMO plans [26]. Friedson [27] concluded that caps on noneconomic damages reduced insurance reimbursements for certain procedures, but providers did not reduce charges to insurers Thorpe [28] reported that state with caps on malpractice claims had insurance premiums that were $17.1 \%$ lower than states without caps. Still, Thorpe questioned whether these reductions were consistent with other goals promoted by the medical liability system. Thus, while perceptions may have provided the political impetus to drive tort liability reforms, the results of the reforms are far from uniform and highly context-dependent.
}

neurology [53-58], or Medicare patients in general [5961]. Our study instead focuses on orthopaedics, an important medical specialty that is understudied in the medical malpractice literature, and is among the medical specialties with the highest risk for medical malpractice claims.

Methodologically, few studies in orthopaedics go beyond survey methods to assess the impact of tort liability on physician treatment choices [21, 62-65]. Beyond orthopaedics, many studies also simply surveyed physicians $[21,38,39,53,55,62,66-68]$, an approach that is likely to elicit self-interested reporting bias from physicians. We will adopt a more objective measure by examining treatment choices in claim databases.

Finally, most studies evaluating the effects of tort liability focus on establishing positive defensive medicine $[21,52,60-62,66,67,69-71]$. By assessing avoidance behavior, our work is also important because of the social burden resulting from avoiding patients requiring care in response to different liability regimes. Our results are the first step to help calibrate the need to balance the tradeoff between patient compensation for iatrogenic injury and the law's undue influence on physician decision-making.

\section{Methods}

\section{Data and sample}

Data for our study included complete Medicare claims and beneficiary summary files from years 2010-2012 for all Medicare patients in the United States with any physician service for one of 192 shoulder-related diagnoses in 2011. To identify incident diagnoses, beneficiaries with any shoulder-related diagnosis within 365-days prior to their index shoulder diagnosis in 2011 were excluded. Beneficiaries diagnosed with proximal humerus fracture (PHF) or atraumatic rotator cuff tear (ARCT) with an index date in 2011 were then identified using specific algorithms described below. Data from 2010 were used to measure baseline patient characteristics and to exclude patients with non-incident shoulder conditions in 2011, and data from 2012 were assessed to identify subsequent use of surgery. This project was approved by the University of South Carolina Institutional Review Board.

\section{Proximal Humerus fracture sample}

The PHF sample was identified by International Classification of Diseases, Ninth Revision, Clinical Modification (ICD-9-CM) diagnosis codes: 812.00, 812.01, 812.02, $812.09,812.10,812.11,812.12,812.13$, and 812.19. The first observed diagnosis date in 2011 was defined as the index date. Beneficiaries with no X-ray of the shoulder or upper extremity within 7-days of their index PHF 
diagnosis were excluded to limit the potential for misdiagnosis.

\section{Atraumatic rotator cuff tear sample}

Presence of ARCT cannot be confirmed without radiologic evidence or surgery. To limit misdiagnosis, patients with no MRI within 90-days of the date of initial shoulder problem in 2011 were excluded. Then, patients with no ICD-9-CM diagnosis code indicating ARCT within 14 days after the date of MRI were excluded. Patients were coded to have received surgery if surgery occurred before any physical therapy in claims during the 104days $(90+14)$ after the index diagnosis date.

Additional inclusion criteria applied to both clinical samples included (1) continuous enrollment in fee-forservice Medicare Part A and Part B, and no enrollment in Medicare Part $\mathrm{C}$, during the study period from 365 days prior to 365 days after the index diagnosis or death; (2) aged 66 years or older on their initial shoulder diagnosis date in 2011; (3) residence within the United States; and (4) complete geographic location information. Full inclusion criteria for both clinical samples are provided in Additional file 1: Appendix A1.

\section{Dependent variables}

Treatment

Treatment windows were defined in the 60-day period following the index PHF diagnosis and 104-day period following the ARCT index event. Patients receiving one of the surgical treatments for fracture (hemiarthroplasty, reverse arthroplasty, open reduction internal fixation) or ARCT (open or arthroscopic rotator cuff repair) were classified as surgery patients. Patients receiving no surgery in the treatment observation window were classified as conservative management patients. Surgery claims were identified using ICD-9-CM Procedure codes and Healthcare Common Procedure Coding System (HCPC S) codes in Medicare Outpatient, MEDPAR, and Carrier files. Complete definitions for all variables are provided in the Additional file 1: Appendix A2.

\section{Independent variables}

\section{State-level tort Laws}

We obtained data on state tort law liability regimes from the Database of State Tort Law Reforms, 1980-2018 (6th Edition) from the University of Texas School of Law [72]. The key explanatory variables of interest are state-level measures of malpractice and tort rules, in three general categories: 1) attribution of fault, 2) limits on liability, and 3) rules of evidence. All of the reform rules (except the comparative negligence rules) decreased physician malpractice liability pressure. Because most of the tort rules that we study were implemented beginning in the late-1990s, we estimated the long-term, stable effects of differences in tort liability rules across states.

Attribution of fault determines how fault is apportioned between multiple defendants (joint and several liability rule) or between defendant and plaintiff when both parties are partially at fault (contributory/comparative negligence). Joint and several liability rule (JSL) is coded as 1 if a state requires patients to sue providers most at fault for their harm rather than the medical team as a whole. For any individual provider, JSL reduced liability pressure because modern medicine is so complex that patients may not necessarily be able identify the correct party to sue.

When both providers and patients are at fault, "comparative negligence" is coded as 1 if a state requires that physicians be at least as much at fault ( $>=50 \%$ at fault) as the patients in order to be liable. "Pure comparative" set to 1 means that a plaintiff can recover from a defendant, even if the plaintiff is much more at fault than the defendant. Unlike other tort rules in our study, the comparative negligence and pure comparative negligence rules increase physician liability pressure by making it possible for patients to recover damages even when patients are partially fault. Prior to the reforms, patients could not recover from a negligent doctor if they were even slightly at fault ("contributory negligence").

Physician liability rules dictate how much monetary liability that a physician at fault faces. "Cap on noneconomic damages" coded as 1 means that there is a cap on monetary damages for non-physical harm, primarily "pain and suffering." "Cap on punitive damages" places a limit on how much patients can receive for physicians' unconscionable behavior that goes beyond mere negligence.

Rules of evidence instruct the jury to consider additional factors when weighing the evidence for monetary awards. "Punitive evidence rule" is coded as 1 if the evidence against extremely negligent physicians must be substantial for them to be held liable. "Collateral source rule" coded as 1 means that juries could obtain information on whether patients were compensated elsewhere (e.g., workers' compensation) to consider when determining the award amount.

The status of the tort rules relevant for each patient was determined based upon each patient's state of residence reported to Medicare in 2011. See Table 1.

\section{Patient clinical and demographic characteristics}

Patient demographic characteristics were identified using Medicare's 2011 Beneficiary Summary. Specific patientlevel variables included age at index, sex, race, and state of residence reported to Medicare in 2011, and Medicaid dual-eligibility status during the index month. Patient health status and comorbidity were measured using the 
Table 1 Status of Tort Liability Rules by State, 2011

\begin{tabular}{|c|c|c|c|c|c|c|c|c|}
\hline & \multicolumn{4}{|c|}{ Attribution of fault } & \multicolumn{2}{|c|}{ Physician liability } & \multicolumn{2}{|l|}{ Evidence } \\
\hline & $\begin{array}{l}\text { JSL } \\
\text { Reform }\end{array}$ & $\begin{array}{l}\text { Contributory } \\
\text { negligence }\end{array}$ & $\begin{array}{l}\text { Comparative } \\
\text { negligence }\end{array}$ & $\begin{array}{l}\text { Pure } \\
\text { comparative } \\
\text { negligence }\end{array}$ & $\begin{array}{l}\text { Cap on non- } \\
\text { economic } \\
\text { damages }\end{array}$ & $\begin{array}{l}\text { Cap on } \\
\text { punitive } \\
\text { damages }\end{array}$ & $\begin{array}{l}\text { Punitive } \\
\text { evidence }\end{array}$ & $\begin{array}{l}\text { Collateral } \\
\text { source rule }\end{array}$ \\
\hline Alabama & No & Yes & No & No & No & Yes & Yes & Yes \\
\hline Arizona & Yes & No & No & Yes & No & No & Yes & Yes \\
\hline Arkansas & Yes & No & Yes & No & No & Yes & Yes & No \\
\hline California & Yes & No & No & Yes & Yes & No & Yes & Yes \\
\hline Colorado & Yes & No & Yes & No & Yes & Yes & Yes & Yes \\
\hline Connecticut & Yes & No & Yes & No & No & No & No & Yes \\
\hline Delaware & No & No & Yes & No & No & No & Yes & Yes \\
\hline Dist. of Columbia & No & Yes & No & No & No & No & Yes & No \\
\hline Florida & Yes & No & No & Yes & Yes & Yes & Yes & Yes \\
\hline Georgia & Yes & No & Yes & No & No & Yes & Yes & No \\
\hline Idaho & Yes & No & Yes & No & Yes & Yes & Yes & Yes \\
\hline Illinois & No & No & No & Yes & No & Yes & No & Yes \\
\hline Indiana & No & No & Yes & No & No & Yes & Yes & Yes \\
\hline lowa & Yes & No & Yes & No & No & No & Yes & Yes \\
\hline Kansas & Yes & No & Yes & No & Yes & Yes & Yes & No \\
\hline Kentucky & Yes & No & No & Yes & No & No & No & No \\
\hline Louisiana & Yes & No & No & Yes & No & Yes & No & No \\
\hline Maine & No & No & Yes & No & No & No & Yes & Yes \\
\hline Maryland & No & Yes & No & No & Yes & No & Yes & No \\
\hline Massachusetts & No & No & Yes & No & Yes & No & No & Yes \\
\hline Michigan & Yes & No & No & Yes & Yes & Yes & No & Yes \\
\hline Minnesota & Yes & No & Yes & No & No & No & Yes & Yes \\
\hline Mississippi & Yes & No & No & Yes & Yes & Yes & Yes & No \\
\hline Missouri & Yes & No & No & Yes & Yes & Yes & Yes & No \\
\hline Montana & Yes & No & Yes & No & Yes & Yes & Yes & Yes \\
\hline Nebraska & Yes & No & Yes & No & No & Yes & No & Yes \\
\hline Nevada & Yes & No & Yes & No & Yes & Yes & Yes & Yes \\
\hline New Hampshire & Yes & No & Yes & No & No & Yes & No & No \\
\hline New Jersey & Yes & No & Yes & No & No & Yes & Yes & Yes \\
\hline New Mexico & Yes & No & No & Yes & No & No & No & No \\
\hline New York & Yes & No & No & Yes & No & No & No & Yes \\
\hline North Carolina & No & Yes & No & No & No & Yes & Yes & No \\
\hline North Dakota & Yes & No & Yes & No & Yes & Yes & Yes & Yes \\
\hline Ohio & Yes & No & Yes & No & Yes & Yes & Yes & Yes \\
\hline Oklahoma & Yes & No & Yes & No & Yes & Yes & Yes & Yes \\
\hline Oregon & Yes & No & Yes & No & No & Yes & Yes & Yes \\
\hline Pennsylvania & N/A & No & Yes & No & No & Yes & Yes & Yes \\
\hline Rhode Island & No & No & No & Yes & No & No & No & Yes \\
\hline South Carolina & Yes & No & Yes & No & Yes & No & Yes & No \\
\hline South Dakota & Yes & No & Yes & No & Yes & No & Yes & Yes \\
\hline Tennessee & Yes & No & Yes & No & No & No & Yes & Yes \\
\hline Texas & Yes & No & Yes & No & Yes & Yes & Yes & No \\
\hline
\end{tabular}


Table 1 Status of Tort Liability Rules by State, 2011 (Continued)

\begin{tabular}{|c|c|c|c|c|c|c|c|c|}
\hline & \multicolumn{4}{|c|}{ Attribution of fault } & \multicolumn{2}{|c|}{ Physician liability } & \multicolumn{2}{|l|}{ Evidence } \\
\hline & $\begin{array}{l}\text { JSL } \\
\text { Reform }\end{array}$ & $\begin{array}{l}\text { Contributory } \\
\text { negligence }\end{array}$ & $\begin{array}{l}\text { Comparative } \\
\text { negligence }\end{array}$ & $\begin{array}{l}\text { Pure } \\
\text { comparative } \\
\text { negligence }\end{array}$ & $\begin{array}{l}\text { Cap on non- } \\
\text { economic } \\
\text { damages }\end{array}$ & $\begin{array}{l}\text { Cap on } \\
\text { punitive } \\
\text { damages }\end{array}$ & $\begin{array}{l}\text { Punitive } \\
\text { evidence }\end{array}$ & $\begin{array}{l}\text { Collateral } \\
\text { source rule }\end{array}$ \\
\hline Utah & Yes & No & Yes & No & Yes & No & Yes & Yes \\
\hline Vermont & Yes & No & Yes & No & No & No & No & No \\
\hline Virginia & No & Yes & No & No & No & Yes & No & No \\
\hline Washington & Yes & No & No & Yes & No & Yes & No & Yes \\
\hline West Virginia & Yes & No & Yes & No & Yes & No & No & Yes \\
\hline Wisconsin & Yes & No & Yes & No & Yes & Yes & Yes & Yes \\
\hline Wyoming & Yes & No & Yes & No & No & No & No & No \\
\hline
\end{tabular}

Charlson Comorbidity Index [73-75] and Frailty Risk Index [76]. Both indices were measured using data from 365 days prior to index. Total Medicare reimbursements by patient over the 365-day period prior to index were placed into quartiles to capture further differences in comorbidity and health status, as well as differences in healthcare-seeking behaviors.

\section{Analytical approach}

This study assessed whether differences in state-level tort rules in 2011 were statistically associated with receipt of surgery as treatment. Our primary approach was to regress the binary variable indicating surgery receipt on patient-level demographic and clinical characteristics and state-level indicators of malpractice and tort laws. We ran separate models for PHF and ARCT patients. The contribution of each state-level malpractice and tort law was assessed by examining their respective parameter estimates and 95\% confidence intervals, as well as by the F-statistic from comparisons with a model excluding the relevant variable. In addition, we reported robust standard errors clustered at the state level.

We chose the linear probability model to estimate and report the associations between tort rules and binomial outcomes because with our large sample size and the Central Limit Theorem, this method enables us to test our regression coefficient using the fewest assumptions related to the error term. According to the Central Limit Theorem, linear regression coefficients are distributed normally when sample size (n) times the probability of the outcome occurring $(\mathrm{p})>5$ and $\mathrm{n}(1-\mathrm{p})>5$ [77]. Both conditions are easily satisfied with the smallest size of our analyses stratum $n=32,163$ and the surgery rate of $\mathrm{p}=$ approximately $20 \%$. In addition, the coefficients that we report from the linear probability model can be interpreted directly as the percentage-point difference in probability of surgery associated with each tort liability rule. Further, our linear probability models were estimated using robust standard errors to alleviate heteroscedasticity concerns [78].
We used SAS software version 9.4 (Cary, NC, USA) to create the analytical samples from the full Medicare dataset, and $\mathrm{R}$ version 3.5.2 (Vienna, Austria) to conduct the statistical analyses.

\section{Results}

In Table 2, we present the summary statistics of key variables in our analytic samples. In our ARCT sample, we had a total of 32,163 individual patients based on our inclusion and exclusion criteria. The corresponding figure is 77,053 for PHF patients. Ultimately, 19.85 and $15.36 \%$ of ARCT and PHF patients respectively received surgery within the follow-up periods. While patients with ARCT were almost evenly split between men (50.23\%) and women (49.77\%), PHF patients were overwhelmingly female $(80.11 \%)$. The remaining summary statistics demonstrate that PHF patients were more likely to have more complex conditions or more vulnerable than ARCT patients, suggesting that physicians likely have greater discretion with treatment choices for ARCT patients. In our data, Medicare expenditures in the year prior to index diagnosis averaged $\$ 15,622.73$ for PHF patients but only $\$ 7593.52$ for ARCT patients. Twice as many PHF versus ARCT patients were dually eligible for Medicare/Medicaid (17.33\% for PHF versus $6.84 \%$ for ARCT). PHF patients were on average approximately 6 years older (80.26 versus 73.97 years old), and were approximately four times more likely to have the highest score of frailty (24.11\% for PHF versus $5.80 \%$ for ARCT). In addition, the average Charlson Comorbidity Index at baseline was 2.57 for PHF patients, and 1.59 for ARCT patients.

\section{Tort-related results}

Our results corroborate the hypothesis that lower malpractice liability is associated with greater utilization of surgical procedures for ARCT and PHF. See Table 3 for ARCT (Panel A). States that had JSL rules (lower liability) had a higher surgery rates by $5 \%$ points (CI $0.03-$ $0.06, p<0.01)$. Similarly, states with a cap on punitive 
Table 2 Summary statistics of analytical samples

\begin{tabular}{|c|c|c|c|c|c|c|c|c|}
\hline \multirow[b]{2}{*}{ Variable } & \multicolumn{4}{|c|}{ Atraumatic Rotator Cuff Tear } & \multicolumn{4}{|c|}{ Proximal Humerus Fracture } \\
\hline & $\%$ & Std Dev & Min & Max & $\%$ & Std. Dev. & Min & Max \\
\hline & $N=32,163$ & & & & $N=76,648$ & & & \\
\hline Surgery within follow-up & $19.85 \%$ & & & & $15.36 \%$ & & & \\
\hline Male & $50.23 \%$ & & & & $19.89 \%$ & & & \\
\hline Dually eligible (full or partial) & $6.84 \%$ & & & & $17.33 \%$ & & & \\
\hline Black & $4.27 \%$ & & & & $3.13 \%$ & & & \\
\hline Hispanic & $1.25 \%$ & & & & $1.35 \%$ & & & \\
\hline Other & $2.39 \%$ & & & & $2.14 \%$ & & & \\
\hline White & $92.10 \%$ & & & & $93.37 \%$ & & & \\
\hline Age & 73.97 & 5.80 & 66.00 & 100.31 & 80.26 & 8.07 & 66.00 & 115.46 \\
\hline Baseline expenditures & 7593.52 & $14,086.28$ & 0.00 & $621,235.40$ & $15,622.73$ & $26,557.62$ & 0.00 & $878,736.70$ \\
\hline Baseline frailty 0 & $61.16 \%$ & & & & $34.14 \%$ & & & \\
\hline Baseline frailty 1 & $24.95 \%$ & & & & $25.90 \%$ & & & \\
\hline Baseline frailty 2 & $8.09 \%$ & & & & $15.85 \%$ & & & \\
\hline Baseline frailty 3 & $5.80 \%$ & & & & $24.11 \%$ & & & \\
\hline Baseline Charlson Index & 1.59 & 1.97 & 0.00 & 18.00 & 2.57 & 2.70 & 0.00 & 24.00 \\
\hline
\end{tabular}

damages or higher levels of evidence required for punitive damages also had higher surgery utilization rates, respectively by $1 \%$ point $(\mathrm{CI} 0.00-0.02, p<0.05)$ and $1 \%$ point $(\mathrm{CI} 0.00-0.03, p<0.05)$.

Conversely, higher provider liability risk is associated with lower surgery rates following diagnosis of ARCT. Comparative negligence and pure comparative negligence both increase physician liability risks relative to those in states that adhere to contributory negligence. Patients in comparative negligence states have 6\%-point lower probability $(\mathrm{CI}-0.08--0.04, p<0.01)$ and those in pure comparative negligence states, 9\%-point lower probability $(\mathrm{CI}-0.11--0.06, p<0.01)$ of undergoing surgery.

We present our results for PHF in Table 3 (Panel B). Again, JSL rule is associated with an increase in surgeries among PHF patients by $2 \%$ points (CI $0.01-0.03, p<$ 0.01). States with caps on punitive damages and higher evidentiary requirement for punitive damages are associated with a $2 \%$-point $(\mathrm{CI} 0.02-0.03, p<0.01)$ and $1 \%$ point $(\mathrm{CI} 0.01-0.02, p<0.01)$ increase in the probability of surgery. For PHF, the comparative negligence rules have a weaker statistical relationship with receipt of surgery, but in the hypothesized direction (a decrease of $1 \%$-point $(-0.02--0.00, p<0.05)$ in the probability of surgery).

\section{Results related to clinical and patient demographic variables}

While we included patient-level demographic and clinical characteristics primarily as control variables, the results are worth exploring as well. Aside from sex, in both patient samples, all other statistically significant coefficients suggest that patients with more complex conditions or in other ways more vulnerable are less likely to receive surgery. Medicare-Medicaid dual eligible patients are less likely to receive surgery by $4 \%$-points (CI $-0.06--0.02, p<0.01)$ for ARCT and by $4 \%$-points $(\mathrm{CI}$ $-0.05--0.03, p<0.01)$ for PHF. Older patients are respectively less likely to undergo surgery for ARCT by $2 \%$ points (CI $-0.03--0.01, p<0.01$, patients $70-75), 7 \%$ points $(\mathrm{CI}-0.08--0.05, p<0.01$, patients $76-79), 12 \%$ points (CI $-0.13--0.10, p<0.01$, patients $80-85)$, and $14 \%$ points (CI $-0.17--0.12, p<0.01$, patients 85 and above). The corresponding figures are $1 \%$ point $(-0.02-$ 0.00 , not statistically significant), $1 \%$ point (CI $-0.02--$ $0.00, p<0.01), 5 \%$ points (CI $-0.06--0.04, p<0.01$ ), and $10 \%$ points $(\mathrm{CI}-0.11--0.09, p<0.01)$ for PHF patients.

Other measures of patient severity corroborate these results. It is reasonable to assume that greater healthcare expenditures and higher Comorbidity Index or Frailty scores at baseline indicate greater patient severity. For ARCT, the top (most severe) quartile or index score is associated with a reduction in surgery, respectively by $4 \%$ points (CI $-0.05--0.03, p<0.01$, highest baseline expenditures), $4 \%$ points (CI $-0.06--0.01, p<0.01$, highest frailty index), and $4 \%$ points (CI $-0.05--0.02$, $p<0.01$, highest Charlson Comorbidity Index). Likewise for PHF, higher levels of frailty and Charlson Index are both associated with lower probabilities of surgery: there was a $5 \%$-point $(\mathrm{CI}-0.06--0.04, p<0.01)$ reduction for frailty group 3 , and a reduction of $2 \%$-points (CI $-0.03--0.02, p<0.01)$ for Charlson Index 4. 
Table 3 Association between legal rules and surgery among Medicare patients with ARCT or PHF

\begin{tabular}{|c|c|c|c|c|c|c|}
\hline \multirow[b]{2}{*}{ Predictors } & \multicolumn{3}{|c|}{ Panel A: ARCT } & \multicolumn{3}{|l|}{ Panel B: PHF } \\
\hline & Estimates & $95 \% \mathrm{Cl}$ & $p$ & Estimates & $95 \% \mathrm{Cl}$ & $p$ \\
\hline (Intercept) & 0.21 & $0.16-0.26$ & $<0.001$ & 0.19 & $0.16-0.22$ & $<0.001$ \\
\hline \multicolumn{7}{|l|}{ Tort Law Variables } \\
\hline JSL rule & 0.05 & $0.03-0.06$ & $<0.001$ & 0.02 & $0.01-0.03$ & $<0.001$ \\
\hline mod comparative & -0.06 & $-0.08--0.04$ & $<0.001$ & -0.01 & $-0.02--0.00$ & 0.031 \\
\hline pure comparative & -0.09 & $-0.11--0.06$ & $<0.001$ & 0 & $-0.01-0.01$ & 0.809 \\
\hline cap nonec & -0.01 & $-0.02-0.00$ & 0.146 & 0 & $-0.00-0.01$ & 0.541 \\
\hline cap puni & 0.01 & $0.00-0.02$ & 0.011 & 0.02 & $0.02-0.03$ & $<0.001$ \\
\hline puni evid & 0.01 & $0.00-0.03$ & 0.016 & 0.01 & $0.01-0.02$ & $<0.001$ \\
\hline coll source & -0.01 & $-0.02-0.01$ & 0.316 & 0 & $-0.01-0.00$ & 0.323 \\
\hline \multicolumn{7}{|l|}{ Control Variables } \\
\hline male & 0.04 & $0.03-0.05$ & $<0.001$ & -0.02 & $-0.03--0.02$ & $<0.001$ \\
\hline dual elig any & -0.04 & $-0.06--0.02$ & $<0.001$ & -0.04 & $-0.05--0.03$ & $<0.001$ \\
\hline race Black & 0.03 & $-0.02-0.08$ & 0.217 & -0.04 & $-0.07--0.00$ & 0.025 \\
\hline race Hispanic & 0.02 & $-0.04-0.08$ & 0.549 & 0 & $-0.03-0.04$ & 0.833 \\
\hline race Other & 0.05 & $-0.01-0.11$ & 0.080 & -0.01 & $-0.04-0.03$ & 0.687 \\
\hline race White & 0.07 & $0.02-0.12$ & 0.004 & 0.02 & $-0.01-0.04$ & 0.27 \\
\hline age group (70-75) & -0.02 & $-0.03--0.01$ & $<0.001$ & -0.01 & $-0.02-0.00$ & 0.082 \\
\hline age group (76-79) & -0.07 & $-0.08--0.05$ & $<0.001$ & -0.01 & $-0.02--0.00$ & 0.003 \\
\hline age group (80-85) & -0.12 & $-0.13--0.10$ & $<0.001$ & -0.05 & $-0.06--0.04$ & $<0.001$ \\
\hline age group (86+) & -0.14 & $-0.17--0.12$ & $<0.001$ & -0.10 & $-0.11--0.09$ & $<0.001$ \\
\hline cost pre $365(\mathrm{Q} 2)^{*}$ & -0.02 & $-0.03--0.00$ & 0.013 & 0 & $-0.00-0.01$ & 0.425 \\
\hline cost pre $365(\mathrm{Q} 3)^{*}$ & -0.03 & $-0.05--0.02$ & $<0.001$ & 0.01 & $-0.00-0.02$ & 0.076 \\
\hline cost pre $365(\mathrm{Q} 4)^{*}$ & -0.04 & $-0.05--0.03$ & $<0.001$ & 0 & $-0.01-0.01$ & 0.994 \\
\hline FRI (1) & -0.01 & $-0.02-0.00$ & 0.093 & -0.02 & $-0.03--0.01$ & $<0.001$ \\
\hline FRI (2) & -0.02 & $-0.03-0.00$ & 0.064 & -0.03 & $-0.03--0.02$ & $<0.001$ \\
\hline FRI (3+) & -0.04 & $-0.06--0.01$ & 0.001 & -0.05 & $-0.06--0.04$ & $<0.001$ \\
\hline cci group (1) & -0.01 & $-0.02-0.00$ & 0.104 & -0.01 & $-0.02-0.00$ & 0.07 \\
\hline cci group (2) & -0.02 & $-0.03--0.00$ & 0.023 & -0.02 & $-0.02--0.01$ & $<0.001$ \\
\hline cci group (3) & -0.02 & $-0.04--0.01$ & 0.007 & -0.01 & $-0.02--0.00$ & 0.019 \\
\hline cci group (4+) & -0.04 & $-0.05--0.02$ & $<0.001$ & -0.02 & $-0.03--0.02$ & $<0.001$ \\
\hline Observations & 32,163 & & & 76,648 & & \\
\hline R2 / R2 adjusted & $0.032 / 0.031$ & & & $0.023 / 0.023$ & & \\
\hline
\end{tabular}

*Q2, Q3, Q4 refer to quartiles

\section{Discussion}

Our findings are consistent with the hypothesis that provider tort liability is associated with use of higher-risk procedures (surgeries). Specifically, higher malpractice pressure (in states with comparative negligence rules) is associated with a lower probability of surgery following an index diagnosis of ARCT and PHF, although the evidence is weaker for the latter. Conversely, lower malpractice pressure (in states with JSL, cap on damages and stricter punitive damage evidentiary rule) is associated with higher probability of surgery for both ARCT and PHF. Overall, our results show that tort liability rules are associated with between a $1 \%$ - to $9 \%$-point difference in surgery rates for these conditions.

Our results extend existing studies by showing that negative, not just positive defensive medicine may exist in a previously understudied but important medical specialty. Existent literature primarily shows a positive association between higher liability pressure and greater use of diagnostic tests $[21,46,62,67,79,80]$. Specific to orthopaedics, Sethi et al. (2010) found that imaging tests ordered primarily due to liability concerns may exceed 
$\$ 2$ billion per year [21]. Our study adds to the literature by showing that orthopaedic surgeons may also increase surgery when the malpractice pressure is lower. This is significant because of the increased possibility of adverse events when a determining factor for riskier surgeries is the malpractice pressure that surgeons face.

Yet, not all studies find evidence of defensive medicine. The inconsistencies in the literature may also be due to different clinical contexts. It is theoretically possible that defensive practices may be greater when substantial discretion in physician treatment choices exists. While we did not test this hypothesis due to a lack of a measure of discretion, it is suggestive that a greater response to joint and several liability rule occurred with ARCT than with PHF (5\% versus $2 \%$ ), with the former (a muscle tear) likely providing more discretion in treatment choices than the latter (a bone fracture). There was also a larger response to attribution of fault rules when considering the generally younger and less vulnerable ARCT patients $(-6 \%$ for comparative negligence and $-9 \%$ for pure comparative negligence) rather than in PHF ( $1 \%$ for modified comparative negligence).

Differences in the measures of malpractice pressure may also account for the range of findings in the literature. Studies that use measures that are more direct than tort reform rules, such as past litigation experience, malpractice premium levels, or elicit perception of malpractice fears directly at the individual physician level, may in fact observe larger associations between tort liability pressure and defensive practices. A recent study, for example, estimated that $20 \%$ of spending for imaging may be due to malpractice concerns by matching physician responses on their perceived malpractice risks and their actual spending or by using physician's recent litigation experience to proxy for malpractice pressure $[59,66]$. Our median results estimating the effect of malpractice fears on surgery utilization are much smaller, ranging from 2 to $4 \%$, possibly due in part to our state-level rather than individuallevel measurement of tort liability pressure.

We now turn to non-tort law factors that affect treatment choice. For both ARCT and PHF, measures of socioeconomic vulnerability and illness severity not only have larger point estimates than the tort variables, they are also collectively larger than the tort variables as a whole. Dual eligibility, older age, greater frailty and Charlson Comorbidity Index together account for a $56 \%$-point of differences in the probability of surgery, versus $22 \%$ for all tort variables in the context of ARCT (when considering only statistically significant relationships). The corresponding numbers are $31 \%$ and $6 \%$ for PHF. This finding suggests that physician decisionmaking is primarily based on patient-specific factors and may only secondarily or minimally be affected by the tort environment.
Overall, viewed in the context of the defensive medicine literature, our results have several implications for policy makers. First, defensive medicine likely exists, but it would be inaccurate to view tort law as purely detrimental. Balancing the intended (reduction in negligence and better health outcomes) and unintended consequences (defensive medicine) is difficult, but categorically restricting patients' ability to seek compensation from negligent doctors may exacerbate the problem of under-compensation among patients who suffered from medical malpractice.

Second, it is important to recognize that the tort liability regime may play only a comparatively small role in driving medical expenditures. Many of the high estimates cited in the literature and popular press are based on extrapolation or physician surveys. The Congressional Budget Office, Mello and colleagues [81], and Rothberg and colleagues [82] all estimate a much lower contribution of "defensive medicine" to healthcare spending, at $0.02,1.8$ and $2.9 \%$ respectively. $^{2}$ Our study, which shows an increase in surgeries when liability pressure is reduced, further shows that tort rules that limit liability may in some areas counterintuitively increase expenditures.

\section{Limitations}

There are several limitations to our work that should be noted. First, because of our cross-sectional design, reverse causality is a concern - that is, states that chose to reform may have had lower surgical rates to begin with because of high malpractice pressure. However, the reform rules whose effects we estimated occurred over 20 years prior, so physicians' surgical rates likely had sufficient time to adjust to the legal rules that were adopted so long ago. On the other hand, the push for tort reform peaked in the late 1990s to early 2000s, so the impact of the legal rule changes may have attenuated since their implementation. We did nevertheless find an effect. Third, a complete analysis of defensive medicine requires studying the effects of tort rules both on utilization and on health outcomes. In this study, we assessed only the former, but we believe that it is important in itself to understand whether tort rules affect behavior. Fourth, the decision to undergo surgery is affected by a host of factors, including both surgeon and patient preferences, both in turn shaped by the external policy environment. In this article, we focused on one aspect of the policy environment that may affect treatment choice - the tort liability regime. However, other

${ }^{2}$ For the $\mathrm{CBO}$ and Mello figures, the estimated annual costs of defensive medicine were divided by total national healthcare expenditures in 2008, the year in which the studies were conducted. Rothberg et al. reported the percentage figure directly in their manuscript. 
policy factors may also influence the decision to perform surgery, including informed consent rules that require greater shared decision-making. These rules may well differ across states, but violating informed consent is a medical malpractice issue for which all of our tort liability rules will determine the financial impact on the surgeon. As a general rule, states with multiple tort reform rules tend to have lower overall restrictions on physician practice choices. Taken together, our study results can therefore also be interpreted as the marginal difference in surgery rates between states that have a less strict versus stricter regulatory environment overall. Finally, regression analyses sometimes produce statistically significant results by chance. However, it is not likely that the same regression specification produces multiple statistically significant results, all in the hypothesized directions, simply by chance.

\section{Conclusion}

Our study suggests that physicians respond to tort liability rules in orthopaedics. Controlling for patient sociodemographic and clinical factors, patients in states with tort rules that lower medical liability risks are more likely to have surgery following an incident diagnosis of ARCT and PHF. Conversely, states with tort rules that increase liability risks are less likely to have surgery for ARCT and PHF. However, our work shows that patientlevel socioeconomic and clinical factors collectively affect the choice to undergo surgery more than the tortrelated variables. Policymakers and state legislators should consider the real cost of defensive medicine when weighing the tradeoff between the desired and unintended consequences of a tort liability system designed to prevent negligence and compensate victims for physician-induced harm.

\author{
Abbreviations \\ ARCT: Atraumatic Rotator Cuff Tear; CAT: Computerized Axial Tomography; \\ Cl: Confidence Intervals; HCPCS: Healthcare Common Procedure Coding \\ System; ICD-9-CM: International Classification of Diseases, Ninth Revision, \\ Clinical Modification; JSL: Joint and Several Liability; MRI: Magnetic \\ Resonance Imaging; MEDPAR: Medicare Provider Analysis and Review; \\ PHF: Proximal Humerus Fracture
}

\section{Supplementary Information}

The online version contains supplementary material available at https://doi. org/10.1186/s12913-021-06544-8.

Additional file 1: Appendix 1. Inclusion and Exclusion Criteria.

Appendix 2. Full Description of Variables.

\section{Acknowledgements}

We thank the Hawkins Foundation, which generously provided funding for the acquisition of ResDAC's Medicare claims data to complete our work. All views and interpretations are those of the authors and do not necessarily reflect the position of our sponsors or employers.

\section{Authors' contributions}

$\mathrm{BC}$ developed the conceptual framework, completed the data requests and applied for the IRB approval; CC and SF conducted the data analyses; BC and JM reviewed the relevant literature; $B C, C C, S F$, and JB drafted and revised the manuscript; all authors commented on and approved the manuscript; $B C$ coordinated the study.

\section{Authors' information}

Brian Chen is an associate professor in the department of Health Services Policy and Management. As an empirical economist and a lawyer, Dr. Chen's research focuses on how legal and financial incentives affect the organization and delivery of health care in the United States and abroad. His recent scholarship includes assessing the impact of attorney advertising on medication adherence and adverse drug reporting, and evaluating the effect of federal drug safety policy on physician prescribing patterns.

Cole Chapman is an assistant professor in Health Services Research at the University of lowa College of Pharmacy. Dr. Chapman is a health econometrician with expertise in methodology for design, implementation, and analysis for evaluating treatment effectiveness, particularly when using observational data from health systems and payers. Dr. Chapman's research focuses on improving understanding of assumptions underlying applied methods for causal inference and how generated evidence can reasonably inform decision making. His recent methods research has examined in current issues in popular applications of instrumental variables approaches; recent applied research has reported variation in physician opioid prescribing patterns and potential downstream impact on use.

Sarah Bauer Floyd is a clinical research assistant professor in the College of Behavioral, Social and Health Sciences at Clemson University. Dr.

Bauer Floyd's research focuses on treatment variation and generating treatment evidence to inform care delivery.

John Mobley is undergraduate research assistant and an Honors College student at University of South Carolina. He is interested in pursuing a medical degree and engage in research studying the impact of health policy interventions on medical practice.

John Brooks is a health economist with a focus on estimating treatment effectiveness using observational healthcare databases. He is the Director of Center for Effectiveness Research in Orthopaedics (CERortho) which is a collaborative effort between the University of South Carolina and Prisma Health to promote comparative effectiveness research (CER) in orthopaedic care. His research has focused on tackling the theoretical and empirical issues surrounding CER.

\section{Funding}

We acknowledge and thank the Hawkins Foundation of Greenville, South Carolina, for support in obtaining the ResDAC Medicare datafiles to complete our research study.

\section{Availability of data and materials}

The Medicare claims data underlying our study can be obtained from ResDAC upon successful application, at https://www.resdac.org. The Database of State Tort Law Reforms, 1980-2018 (6th Edition) from the University of Texas School of Law can be accessed at https://law.utexas.edu/ faculty/ravraham/dstlr.php.

\section{Declarations}

\section{Ethics approval and consent to participate}

This study was based on existing secondary data, and was approved by the University of South Carolina Institutional Review Board.

\section{Consent for publication}

N/A

\section{Competing interests}

The authors declare no competing interests.

\section{Author details}

'Department of Health Services Policy and Management, University of South Carolina, 915 Greene Street Suite 354, Columbia, SC 29205, USA.

${ }^{2}$ Department of Pharmacy Practice and Science, University of lowa, 345 CPB,

180 South Grand Ave, lowa City, IA 52242, USA. ${ }^{3}$ College of Behavioral, Social 
and Health Sciences, Clemson University, 116 Edwards Hall, Clemson, SC 29634, USA. ${ }^{4}$ University of South Carolina School of Medicine Greenville , 607 Grove Rd, SC 29605 Greenville, USA. ${ }^{5}$ Department of Health Services Policy and Management, University of South Carolina, 915 Greene Street Suite 302, Columbia, SC 29205, USA.

\section{Received: 7 January 2021 Accepted: 13 May 2021}

Published online: 28 May 2021

\section{References}

1. Andersson G, Bouchard J, Bozic K, Campbell Jr R, Cisternas M, Correa A, Cosman F, Cragan J, D'Andrea K, Doernberg N: United States bone and joint decade: the burden of musculoskeletal diseases in the United States. Rosemont: American Academy of Orthopaedic Surgeons 2008:97-161.

2. Palazzo C, Ravaud J-F, Papelard A, Ravaud P, Poiraudeau S, Vos T, et al. The burden of musculoskeletal conditions. PLoS One. 2014;9(3):e90633. https:// doi.org/10.1371/journal.pone.0090633.

3. Urwin M, Symmons D, Allison T, Brammah T, Busby H, Roxby M, et al. Estimating the burden of musculoskeletal disorders in the community: the comparative prevalence of symptoms at different anatomical sites, and the relation to social deprivation. Ann Rheum Dis. 1998;57(11):649-55. https:// doi.org/10.1136/ard.57.11.649.

4. Soucacos PN, Johnson EO, Babis G. Randomised controlled trials in orthopaedic surgery and traumatology: overview of parameters and pitfalls. Injury-Int J Care Inj. 2008;39(6):636-42. https://doi.org/10.1016/j. injury.2008.02.011

5. Campbell AJ, Bagley A, Van Heest A, James MA: Challenges of Randomized Controlled Surgical Trials. Orthop Clin North Am 2010, 41(2):145.

6. Carr AJ. Evidence-based orthopaedic surgery: what type of research will best improve clinical practice? J Bone Joint Surg Br. 2005;87(12):1593-4.

7. Inacio MC, Paxton EW, Dillon MT. Understanding Orthopaedic registry studies: a comparison with clinical studies. J Bone Joint Surg Am. 2016;98(1): e3. https://doi.org/10.2106/JBJS.N.01332

8. Broekman ML, Carriere ME, Bredenoord AL. Surgical innovation: the ethical agenda: a systematic review. Medicine (Baltimore). 2016;95(25):e3790. https://doi.org/10.1097/MD.0000000000003790.

9. Harris JD, Cvetanovich G, Erickson BJ, Abrams GD, Chahal J, Gupta AK, et al. Current status of evidence-based sports medicine. Arthroscopy. 2014;30(3): 362-71. https://doi.org/10.1016/j.arthro.2013.11.015.

10. Parsons NR, Price CL, Hiskens R, Achten J, Costa ML. An evaluation of the quality of statistical design and analysis of published medical research: results from a systematic survey of general orthopaedic journals. BMC Med Res Methodol. 2012;12(1):60. https://doi.org/10.1186/1471-2288-12-60.

11. Bederman SS, Chundamala J, Wright JG. Randomized clinical trials in orthopaedic surgery: strategies to improve quantity and quality. J Am Acad Orthop Surg. 2010;18(8):454-63. https://doi.org/10.5435/00124635-201 008000-00002.

12. Obremskey WT, Pappas N, Attallah-Wasif E, Tornetta P 3rd, Bhandari M Level of evidence in orthopaedic journals. J Bone Joint Surg Am. 2005; 87(12):2632-8. https://doi.org/10.2106/00004623-200512000-00006.

13. Pappou IP, Schmidt CC, Jarrett CD, Steen BM, Frankle MA. AAOS appropriate use criteria: optimizing the Management of Full-Thickness Rotator Cuff Tears. J Am Acad Orthop Surg. 2013;21(12):772-5. https://doi.org/10.5435/ 00124635-201312000-00008.

14. Wright JG, Swiontkowski M, Heckman JD. Levels of evidence. J Bone Joint Surg Br. 2006;88(9):1264.

15. Jevsevar DS. Treatment of osteoarthritis of the knee: evidence-based guideline, 2nd edition. J Am Acad Orthop Surg. 2013;21(9):571-6.

16. Weinstein JN, Bronner KK, Morgan TS, Wennberg JE: Trends and geographic variations in major surgery for degenerative diseases of the hip, knee, and spine. Health Aff (Millwood) 2004, Suppl Variation:VAR81-89.

17. Weinstein JN, Lurie JD, Olson PR, Bronner KK, Fisher ES. United States' trends and regional variations in lumbar spine surgery: 1992-2003. Spine (Phila Pa 1976). 2006;31(23):2707-14. https://doi.org/10.1097/01.brs. 0000248132.15231.fe.

18. Haughom BD, Goldstein Z, Hellman MD, Yi PH, Frank RM, Levine BR. An analysis of references used for the Orthopaedic in-training examination: what are their levels of evidence and journal impact factors? Clin Orthop Relat Res. 2014;472(12):4024-32. https://doi.org/10.1007/s11999-014-3895-0.

19. Bernstein J, Kenniston JA, Nydick JA, Zgonis MH, Beredjiklian PK. Levels of evidence are low for clinical management questions on the orthopaedic in- training examination. J Bone Joint Surg Am. 2010;92(2):508-11. https://doi. org/10.2106/JBJS.I.00530

20. Jena $A B$, Seabury S, Lakdawalla $D$, Chandra A. Malpractice risk according to physician specialty. N Engl J Med. 2011;365(7):629-36. https://doi.org/10.1 056/NEJMsa1012370

21. Sethi MK, Obremskey WT, Natividad H, Mir HR, Jahangir AA. Incidence and costs of defensive medicine among orthopedic surgeons in the United States: a national survey study. Sports Med. 2012;421:35.35.

22. Zuger A. Dissatisfaction with medical practice. N Engl J Med. 2004;350(1): 69-75. https://doi.org/10.1056/NEJMsr031703.

23. Studdert D, Mello M, Sage W, DesRoches C, Peugh J, Zapert K, Brennan T: Defensive medicine among high-risk specialist physicians in a volatile malpractice environment. In., vol. 293: Am Med Assoc; 2005: 2609-2617.

24. Sloan FA, Shadle JH. Is there empirical evidence for "defensive medicine"? A reassessment. J Health Econ. 2009;28(2):481-91. https://doi.org/10.1016/j. jhealeco.2008.12.006

25. Sloan FA, Chepke LM: Medical malpractice. Cambridge, Mass.: MIT Press; 2008.

26. Avraham R, Dafny LS, Schanzenbach MM. The impact of tort reform on employer-sponsored health insurance premiums. J Law Econ Organ. 2012 28(4):657-86. https://doi.org/10.1093/jleo/ewq017.

27. Friedson Al. Medical malpractice damage caps and provider reimbursement Health Econ. 2017;26(1):118-35. https://doi.org/10.1002/hec.3283.

28. Thorpe KE: The medical malpractice 'crisis': recent trends and the impact of state tort reforms. Health Aff (Millwood) 2004, Suppl Web Exclusives:W4-20-30.

29. American Tort Reform Association's Mission: Real Justice in Our Courts [http://www.atra.org/about, Accessed 4 June 2014].

30. Obremskey WT. Defensive Orthopaedic imaging: is it real? JBJS Orthopaedic Highlights: Trauma. 2012;2(6):e4.

31. Bhattacharyya T. Evidence-based approaches to minimizing malpractice risk in orthopedic surgery. Orthopedics. 2005;28(4):378-81. https://doi.org/10.392 8/0147-7447-20050401-12.

32. Baldwin L, Hart L, Lloyd M, Fordyce M, Rosenblatt R. Defensive medicine and obstetrics. JAMA. 1995;274(20):1606-10. https://doi.org/10.1001/jama.1 995.03530200042034.

33. Cheng YW, Snowden JM, Handler SJ, Tager IB, Hubbard AE, Caughey AB. Litigation in obstetrics: does defensive medicine contribute to increases in cesarean delivery? J Matern Fetal Neonatal Med. 2014;27(16):1668-75. https://doi.org/10.3109/14767058.2013.879115.

34. Clark SL, Belfort MA, Dildy GA, Meyers JA. Reducing obstetric litigation through alterations in practice patterns. Obstet Gynecol. 2008;112(6):1279_ 83. https://doi.org/10.1097/AOG.0b013e31818da2c7.

35. Frakes M. Defensive medicine and obstetric practices. J Empir Leg Stud. 2012;9(3):457-81. https://doi.org/10.1111/j.1740-1461.2012.01259.x.

36. Gimm GW. The impact of malpractice liability claims on obstetrical practice patterns. Health Serv Res. 2010;45(1):195-211. https://doi.org/10.1111/j.14756773.2009.01062.x

37. Localio A, Lawthers A, Brennan T, Laird N, HERBERT L, Peterson L, et al. Relation between malpractice claims and adverse events due to negligence: results of the Harvard medical practice study III. Obstetrical Gynecol Survey. 1992;47(1):35-7. https://doi.org/10.1097/00006254-199201000-00014.

38. Mello MM, Kelly CN. Effects of a professional liability crisis on residents' practice decisions. Obstet Gynecol. 2005;105(6):1287-95. https://doi.org/10.1 097/01.AOG.0000163255.56004.b5.

39. Rosenblatt RA, Wright CL. Rising malpractice premiums and obstetric practice patterns: the impact on family physicians in Washington state. West J Med. 1987;146(2):246-8.

40. Sloan F, Entman S, Reilly B, Glass C, Hickson G, Zhang H. Tort liability and obstetricians' care levels. Int Review Law Econ. 1997;17(2):245-60. https:// doi.org/10.1016/S0144-8188(97)00005-7.

41. Tussing AD, Wojtowycz MA. Malpractice, defensive medicine, and obstetric behavior. Med Care. 1997;35(2):172-91. https://doi.org/10.1097/00005650-1 99702000-00007.

42. Currie J, MacLeod W. First do no harm? Tort reform and birth outcomes*. Q J Econ. 2008;123(2):795-830. https://doi.org/10.1162/qjec.2008.123.2.795.

43. Yang YT, Mello MM, Subramanian S, Studdert DM. Relationship between malpractice litigation pressure and rates of cesarean section and vaginal birth after cesarean section. Med Care. 2009;47(2):234-42. https://doi.org/1 0.1097/MLR.0b013e31818475de.

44. Taylor AJ. The effect of changes in tort Laws on cesarean section rates in the United States: University of Alabama at Birmingham; 2011. 
45. Edwards $C T$. The impact of no-fault tort reform on physician decisionmaking: a look at Virginia's birth injury program. Rev Jur UPR. 2011;80:285.

46. Dubay $L$, Kaestner $R$, Waidmann $T$. The impact of malpractice fears on cesarean section rates. J Health Econ. 1999;18(4):491-522. https://doi.org/1 0.1016/S0167-6296(99)00004-1.

47. Rock SM. Malpractice premiums and primary cesarean section rates in New York and Illinois. Public Health Rep. 1988;103(5):459-63.

48. Roth LM. What's the rush? Tort laws and elective early-term induction of labor. J Health Soc Behav. 2016;57(4):486-501. https://doi.org/10.1177/ 0022146516669971.

49. Cano-Urbina J, Montanera D. Do tort reforms impact the incidence of birth by cesarean section? A reassessment. Int J Health Econ Manag. 2017;17(1): 103-12. https://doi.org/10.1007/s10754-016-9202-8.

50. Avraham $R$, Schanzenbach $M$. The impact of tort reform on intensity of treatment: evidence from heart patients. J Health Econ. 2015;39:273-88. https://doi.org/10.1016/j.jhealeco.2014.08.002.

51. Kessler D, McClellan M. Do doctors practice defensive medicine? Q J Econ. 1996;111(2):353-90. https://doi.org/10.2307/2946682.

52. Katz DA, Williams GC, Brown RL, Aufderheide TP, Bogner M, Rahko PS, et al. Emergency physicians' fear of malpractice in evaluating patients with possible acute cardiac ischemia. Ann Emerg Med. 2005;46(6):525-33. https:// doi.org/10.1016/j.annemergmed.2005.04.016.

53. Nahed BV, Babu MA, Smith TR, Heary RF. Malpractice liability and defensive medicine: a national survey of neurosurgeons. PLoS One. 2012;7(6):e39237. https://doi.org/10.1371/journal.pone.0039237.

54. Smith TR, Habib A, Rosenow JM, Nahed BV, Babu MA, Cybulski G, et al. Defensive medicine in neurosurgery: does state-level liability risk matter? Neurosurgery. 2014;76(2):105-14.

55. Smith TR, Hulou MM, Yan SC, Cote DJ, Nahed BV, Babu MA, et al. Defensive medicine in neurosurgery: the Canadian experience. J Neurosurg. 2016; 124(5):1524-30. https://doi.org/10.3171/2015.6.JNS15764.

56. Cote DJ, Karhade AV, Larsen AM, Castlen JP, Smith TR. Neurosurgical defensive medicine in Texas and Illinois: a tale of 2 states. World Neurosurg. 2016:89:112-20. https://doi.org/10.1016/j.wneu.2016.01.080

57. Yan SC, Hulou MM, Cote DJ, Roytowski D, Rutka JT, Gormley WB, et al. International defensive medicine in neurosurgery: comparison of Canada, South Africa, and the United States. World Neurosurg. 2016;95:53-61. https://doi.org/10.1016/j.wneu.2016.07.069.

58. Yan SC, Hulsbergen AF, Muskens IS, van Dam M, Gormley WB, Broekman $M L$, et al. Defensive medicine among neurosurgeons in the Netherlands: a national survey. Acta Neurochir. 2017;159(12):2341-50. https://doi.org/10.1 007/s00701-017-3323-9.

59. Reschovsky JD, Saiontz-Martinez CB. Malpractice claim fears and the costs of treating medicare patients: a new approach to estimating the costs of defensive medicine. Health Serv Res. 2018;53(3):1498-516. https://doi.org/1 0.1111/1475-6773.12660

60. Farmer SA, Moghtaderi A, Schilsky S, Magid D, Sage W, Allen N, et al. Association of Medical Liability Reform with Clinician Approach to coronary artery disease management. JAMA Cardiol. 2018;3(7):609-18. https://doi. org/10.1001/jamacardio.2018.1360.

61. Waxman DA, Ridgely MS, Heaton P. The effect of malpractice reform on emergency department care. N Engl J Med. 2015;372(2):192. https://doi. org/10.1056/NEJMc1413881.

62. Osti M, Steyrer J. A national survey of defensive medicine among orthopaedic surgeons, trauma surgeons and radiologists in a ustria: evaluation of prevalence and context. J Eval Clin Pract. 2015;21(2):278-84. https://doi.org/10.1111/jep.12305

63. Upadhyay A, York S, Macaulay W, McGrory B, Robbennolt J, Bal BS: Medical Malpractice in Hip and Knee Arthroplasty. J Arthroplasty 2007, 22(6, Supplement):2-7.e4.

64. Bishop TF, Federman AD, Keyhani S. Physicians' views on defensive medicine: a National Survey. JAMA Intern Med. 2010;170(12):1081-3.

65. Klimo G, Daum W, Brinker M, McGuire E, Elliott M. Orthopedic medical malpractice: an attorney's perspective. Am J Orthopedics. 2000;29(2):93-7.

66. Miller RA, Sampson NR, Flynn JM. The prevalence of defensive orthopaedic imaging: a prospective practice audit in Pennsylvania. JBJS. 2012;94(3):e18. https://doi.org/10.2106/JBJS.K.00646

67. Kanzaria HK, Hoffman JR, Probst MA, Caloyeras JP, Berry SH, Brook RH. Emergency physician perceptions of medically unnecessary advanced diagnostic imaging. Acad Emerg Med. 2015;22(4):390-8. https://doi.org/1 0.1111 /acem. 12625 .
68. O'Neill L, Kuder J. Explaining variation in physician practice patterns and their propensities to recommend services. Med Care Res Rev. 2005;62(3): 339-57. https://doi.org/10.1177/1077558705275424.

69. Smith-Bindman R, McCulloch CE, Ding A, Quale C, Chu PW. Diagnostic imaging rates for head injury in the ED and states' medical malpractice tort reforms. Am J Emerg Med. 2011;29(6):656-64. https://doi.org/10.1016/j.a jem.2010.01.038

70. Li S, Dor A, Deyo D, Hughes DR. The impact of state tort reforms on imaging utilization. J Am Coll Radiol. 2017;14(2):149-56. https://doi.org/10.1 016/j.jacr.2016.10.002.

71. Carrier ER, Reschovsky JD, Katz DA, Mello MM. High physician concern about malpractice risk predicts more aggressive diagnostic testing in officebased practice. Health Aff. 2013;32(8):1383-91. https://doi.org/10.1377/hltha ff.2013.0233

72. Database of State Tort Law Reforms 1980-2018 (6th Edition) [https://law. utexas.edu/faculty/ravraham/dstlr.php]. Accessed 20 Sept 2018.

73. Roffman CE, Buchanan J, Allison GT. Charlson comorbidities index. J Physiother. 2016;62(3):171. https://doi.org/10.1016/j.jphys.2016.05.008.

74. Charlson M, Pompei P, Ales K, Mac Kenzie C. A new method of classifying prognostic comorbidity in longitudinal studies: development and validation. J Chronic Dis. 1987;40(5):373-83. https://doi.org/10.1016/ 0021-9681(87)90171-8.

75. Charlson M, Szatrowski T, Peterson J, Gold J. Validation of a combined comorbidity index. J Clin Epidemiol. 1994;47(11):1245-51. https://doi.org/1 0.1016/0895-4356(94)90129-5.

76. Ng TP, Feng L, Nyunt MS, Larbi A, Yap KB. Frailty in older persons: multisystem risk factors and the frailty risk index (FRI). J Am Med Dir Assoc. 2014;15(9):635-42. https://doi.org/10.1016/j.jamda.2014.03.008.

77. Lumley T, Diehr P, Emerson S, Chen L. The importance of the normality assumption in large public health data sets. Annu Rev Public Health. 2002; 23(1):151-69. https://doi.org/10.1146/annurev.publhealth.23.100901.140546.

78. White $\mathrm{H}$. A heteroskedasticity-consistent covariance matrix estimator and a direct test for heteroskedasticity. Econometrica. 1980;48(4):817-38. https:// doi.org/10.2307/1912934.

79. Carrier ER, Reschovsky JD, Mello MM, Mayrell RC, Katz D. Physicians' fears of malpractice lawsuits are not assuaged by tort reforms. Health Aff. 2010;29(9): 1585-92. https://doi.org/10.1377/hlthaff.2010.0135.

80. Frakes $\mathrm{M}$. The impact of medical liability standards on regional variations in physician behavior: evidence from the adoption of national-standard rules. Am Econ Rev. 2013;103(1):257-76. https://doi.org/10.1257/aer.103.1.257.

81. Mello MM, Chandra A, Gawande AA, Studdert DM. National Costs of the Medical Liability System. Health Aff. 2010;29(9):1569-77. https://doi.org/10.13 77/hlthaff.2009.0807.

82. Rothberg MB, Class J, Bishop TF, Friderici J, Kleppel R, Lindenauer PK. The cost of defensive medicine on 3 hospital medicine services. JAMA Intern Med. 2014;174(11):1867-8. https://doi.org/10.1001/jamainternmed.2014.4649.

\section{Publisher's Note}

Springer Nature remains neutral with regard to jurisdictional claims in published maps and institutional affiliations.

Ready to submit your research? Choose BMC and benefit from:

- fast, convenient online submission

- thorough peer review by experienced researchers in your field

- rapid publication on acceptance

- support for research data, including large and complex data types

- gold Open Access which fosters wider collaboration and increased citations

- maximum visibility for your research: over $100 \mathrm{M}$ website views per year

At $\mathrm{BMC}$, research is always in progress.

Learn more biomedcentral.com/submission 